\title{
Profit sharing as entry deterrence mechanism
}

\author{
Domenico Buccella ${ }^{1}$
}

Received: 26 November 2014 / Accepted: 25 January 2016 /Published online: 5 February 2016

(C) The Author(s) 2016. This article is published with open access at Springerlink.com

\begin{abstract}
In a right-to-manage framework, this paper analyzes the optimal choice of the pay scheme (profit sharing vs. fixed wage) in a unionized duopoly with potential market entry and decentralized bargaining. The paper shows that, depending on the institutional features, both pay systems can arise as equilibria in Nash strategies. Under duopoly with committed bargaining, the fixed wage is the Nash equilibrium; with flexible bargaining, an agreement between the incumbent firm and its union about profit sharing arises as Nash equilibrium, if the union is not too strong. A monopoly with threat of entry reinforces the selection of profit sharing as a deterrent mechanism.
\end{abstract}

Keywords Union-oligopoly bargaining $\cdot$ Fixed wage $\cdot$ Profit-sharing $\cdot$ Entry deterrence effect

JEL classification $\mathrm{J} 51 \cdot \mathrm{L} 13 \cdot \mathrm{L} 20$

\section{Introduction}

Negotiations between firms and unions are at the core of labor market institutions in advanced economies. The economics literature has addressed a consistent part of the analysis to the scope of bargaining: concerning wages only, or both employment and wage rates. The former refers to the right-to-manage model (RTM, Nickell and Andrews 1983): the wage rate is set during the negotiations but firms retain the right to decide employment levels; the equilibrium solution is on the firms' labor demand. The latter refers to the efficient bargaining model (EB, McDonald and Solow 1981): firms and unions negotiate at the same time over wages and employment; the Paretoefficient equilibrium lies on the contract curve's locus.

Electronic supplementary material The online version of this article (doi:10.1007/s10258-016-0113-x) contains supplementary material, which is available to authorized users.

Domenico Buccella

buccella@kozminski.edu.pl

1 Department of Economics, Leon Kozminski University, 57/59 Jagiellonska St., 03-301 Warsaw, Poland 
A few scholars have studied the strategic choice of the bargaining agenda in unionized oligopolies. Authors such as Yang (1995), Vannini and Bughin (2000), and Petrakis and Vlassis (2000) focus on the question whether firms and unions prefer to negotiate under the EB or RTM model. Furthermore, Bughin (1999) and Buccella (2011) argue that the bargaining parties may strategically choose their agenda to deter market entry. Those models assume unions and firms negotiate over fixed wages. However, fixed wages are not the unique pay scheme available. In fact, workers may get compensations according to performance related pay schemes, notably profitsharing. For instance, according to OECD data (1995), $15 \%$ of the US companies with more than 100 workers and $15 \%$ of the Canadian companies with more than 20 workers have a profit-sharing scheme. As regards the European Union, the incidence of companies with more than 10 employees with a profit sharing scheme ranges from $3 \%$ of Italy to $35 \%$ of France (Eurofound 2010), whereas the percentage of companies with more than 250 employees adopting profit sharing schemes ranges from 2,9\% of Greece to 23,6 \% of Finland (Eurofound 2012).

While the subject of the strategic bargaining agenda selection to deter market entry is present in the economic literature, up to the present, the idea that pay schemes can be utilized as entry deterrence mechanism for a given bargaining framework has not been explored. Under fairly standard hypotheses (labor unique factor of production with constant return to scales technology, risk neutral union, linear market demand), this work sets out to investigate if, in a unionized industry characterized by RTM negotiations, the introduction of a profit sharing scheme may be used as a strategic tool to deter entry.

Some research has studied the introduction of profit sharing schemes in union-firm bargaining. Pioneering contributions are those of Hoel and Moene (1988), Anderson and Devereux (1989) and Pemberton (1991) which explore the effects of introducing profit sharing in the context of a unionized monopoly. Notably, Anderson and Devereux (1989) have shown that in a unionized monopoly the bargaining outcomes of profit sharing equal those of the EB model. As regards unionized oligopolies, only a limited number of works have considered the use of profit-sharing as a strategic tool. Fung (1989) analyzes a unionized oligopoly. This author assumes that, in a firm adopting the profit-sharing scheme, the firm unilaterally fixes the profit-sharing parameter and the union unilaterally sets the wage rate. Sørensen (1992) analyzes decentralized negotiations under the RTM model between two union-firm units with asymmetric bargaining power. Firms may either choose a fixed wage or a profit-sharing scheme. In the case of profit sharing, the firm and the union bargain over the base wage and the share parameter. The paper investigates 1 ) which pay scheme arises endogenously as Nash equilibrium and 2) the welfare increasing effects for society of introducing profit-sharing. Göddeke (2010) studies the incentives for firms and unions to introduce profit-sharing schemes as a strategic means to improve single bargaining units position in a Cournot oligopoly. The work analyzes both decentralized and centralized wage bargaining, focusing on the stability of these institutional arrangements. ${ }^{1}$ However, none of the above mentioned works discusses market entry issues.

\footnotetext{
${ }^{1}$ To the best of the author knowledge, only few papers have analyzed the case of industry-wide unions negotiating profit-sharing schemes. Jackman (1988) finds that the introduction of profit-sharing in an imperfectly competitive sector unambiguously reduces the unemployment rate. Assuming a monopoly union and Bertrand competition in the product market, Dhillon et al. (2001) shows that the union may have incentives to reduce employment, decreasing total output and causing an increase in total profits.
} 
On the other hand, Bughin (1999), Buccella (2011), and Buccella and Fanti (2015) deal with the subject of market entry deterrence in a unionized sector. Bughin (1999) investigates the optimal strategic choice of the bargaining agenda for different market structures (duopoly vs. monopoly with threat of potential entry) and constraints (committed vs. flexible bargaining) in a Cournot oligopoly with decentralized negotiations. Extending Bughin's (1999) framework to a conjectural variation model, Buccella (2011) shows that EB emerges as the industry equilibrium without conflict of interests between the bargaining parties only for entry deterrence reasons. In all other cases, conflicts of interest arise due to the difference in the parties' dominant strategies, whatever is the degree of competitiveness within the industry. Buccella and Fanti (2015) show that, under an alternative timing of the game with respect to Bughin (1999) and Buccella (2011), a rich set of equilibrium outcomes arises, including multiple and even (as regards the union's preferences on the bargaining agenda) asymmetric equilibria. Moreover, the set of cases in which the equilibrium implies the choice of EB is substantially larger than in Buccella (2011).

The present work builds on Sørensen (1992), Bughin (1999), Buccella (2011) and Buccella and Fanti (2015). In a unionized duopoly with homogeneous goods and decentralized bargaining, the equilibrium pay scheme is sensitive to the market structure, the constraints on the bargaining scope choice and the parties' relative power. The sub-game perfect Nash equilibria pay schemes are determined through a sequential game between the incumbent and the entrant. The paper analyzes the optimal strategic choice of the pay scheme for different market structures and constraints for a given RTM bargaining framework. Two institutional frameworks are considered: 1) the flexible bargaining, where the entrant can choose its pay scheme; and 2) the committed bargaining, where the incumbent chooses its payment scheme; then, the entrant is obliged to "join the pack" and adopt the industry common practice. The key results are as follows.

First, it is shown that the bargaining units may have common interest toward profitsharing, both when oligopoly is the given market structure and under the threat of entry. In fact, whatever is the entry mode in the industry, for a given bargaining framework (in this context, the RTM model), there are situation such that the flexibility of choosing the pay scheme eliminates the internal conflict of interests among the bargaining parties. This result contrasts with the findings of Buccella (2011) where, for a given payment scheme (the fixed wage), the flexibility of choosing strategically the scope of the bargaining agenda among EB or RTM never eradicates the internal parties' conflict of interests. Second, this paper highlights the possibility of using the payment schemes as strategic tools to deter market entry: the incumbent firm and its union can reach an agreement toward the profit sharing scheme to deter the potential entry of a competitor in the product market. These findings are significant because, if the labor market institutions of a country do not contemplate that employment enters the bargaining protocol and, as a consequence, the union-firm pairs cannot strategically choose the bargaining agenda, the pay schemes can become an effective entry deterrence mechanism.

The remainder of the paper is organized as follows. Section 2 describes the model and derives the sub-game perfect bargaining regime arising in equilibrium. Finally, Section 3 draws some conclusions. 


\section{The model and the results}

In an imperfectly competitive sector of an economy there are two firms: the incumbent, firm 1 , and the potential entrant, firm 2. Each firm produces homogeneous goods and faces its labor union, which is assumed to be large enough to meet the firm's labor demand, with $N_{i}$, $i=1,2$, exogenously given members. Labor, $l$, is the unique factor of production with a constant returns-to-scale technology, $q_{i}=l_{i}$, where $q_{i}$ is the firm $i$ 's output. ${ }^{2}$ Hence, employment and quantity can be used interchangeably. The gross profit function of firm $i$ is as follows

$$
\pi_{i}=\left(p-\varpi_{i}\right) q_{i}, i=1,2
$$

where $p$ is the price and $\varpi_{i}$ is the base wage in firm $i$. Following Sørensen (1992), the firm's owners are assumed risk neutral so that their utility levels can be measured by income levels. Thus, net profits are

$$
\Lambda_{i}=\left(1-\lambda_{i}\right)\left(p-\varpi_{i}\right) q_{i}, i=1,2
$$

with $\lambda_{i}$ defining the share of profits going to workers. The labor union is also risk neutral and maximizes the total wage bill

$$
\Omega_{i}=w_{i} q_{i}, i=1,2
$$

where $w_{i}$ is the total payment per worker in firm $i$, and $q_{i}=l_{i} \leq N_{i}$ is employment in the firm. Under profit sharing, the total income per worker is given by

$$
w_{i}=\varpi_{i}+\left(\lambda_{i} \pi_{i} / q_{i}\right)
$$

where $\varpi_{i}$ is the base wage and $\lambda_{i} / q_{i}$ is the equal share of the firm gross profits paid to employed workers. ${ }^{3}$ Therefore, with profit sharing each firm-level union has the control over two independent variables in the bargaining process: the base wage $\varpi_{i}$ and the share parameter $\lambda_{i}$ (Fig. 1).

The (inverse) linear demand for goods is

$$
p=1-Q
$$

with $p$ denoting the market price (both the demand parameters $a$ and $b$ are normalized to 1) and $Q=\sum_{i} q_{i}=\sum_{i} l_{i}, \quad i=1,2$ total production. Following Bughin (1999) and Buccella

\footnotetext{
${ }^{2}$ Traditional one incumbent/one potential entrant models can be substantiated by differences in the efficiency level across firms. Since Bain (1956), scale economies are recognized as potential sources of barrier to entry as in many cases the incumbent is a large firm, whereas a new entrant is typically small and, thus, may be less efficient. Mukherjee and Wang (2013) also consider different efficiency levels across firms; however, these authors investigate the case of a potential entrant that is more efficient than the incumbent, without any scale motivation. This work retains the assumption of constant returns-to-scale because the central issue is the detection of a strategic role for profit sharing in preventing entry, without neither scale, nor efficiency considerations.

${ }^{3}$ Chang and Bjornstad (1993) shows that the introduction of the profit sharing scheme alters the choice of the effort level of the workers and, therefore, improves their productivity levels; some recent empirical studies seem to confirm that profit sharing is positively related with labor productivity (D'Art and Turner 2004; Gielen et al. 2010). However, to simplify the model and highlight the point that the pay schemes can be used as entry deterrence mechanism, as in Sørensen (1992) the analysis abstracts from this aspect.
} 


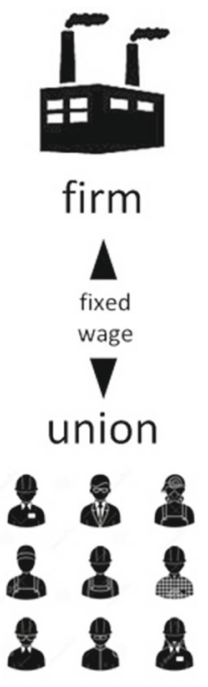

Fixed wage bargaining unit

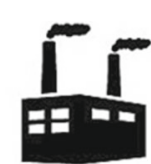

firm

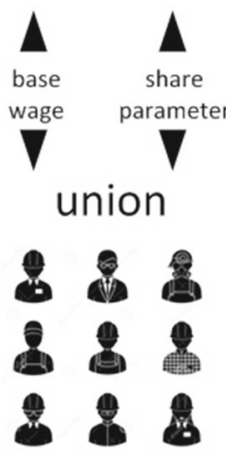

Profit sharing bargaining unit

Fig. 1 Decentralized wage negotiations

(2011), entry in an industry is modeled as a change from a monopoly to a duopoly market structure. Therefore, given equations (2) and (5), the firm's net profits are

$$
\begin{gathered}
\Lambda_{1}=\left(1-\lambda_{1}\right)\left(1-Q-\varpi_{1}\right) q_{1} \\
\Lambda_{2}=\left(1-\lambda_{2}\right)\left(1-Q-\varpi_{2}\right) q_{2}-E
\end{gathered}
$$

for firm 1 and 2, respectively. $E$ represents an exogenous fixed cost for the potential entrant. Notice that, in the case of fixed wage, $\lambda_{i}=0$ and $\varpi_{i}=w_{i}$ : each union attempts to achieve a high level of its utility only through the negotiation of the base wage (Fig. 1).

The bargaining structure in the industry is decentralized at the firm-level. The wage setting occurs before the employment decisions. Hence, the firm hires workers according to its necessities: the prevalent framework in the industry is the RTM model. The bargaining solution is modelled by the generalized Nash Product. In the case of the fixed wage scheme, the maximization problem is

$$
\varpi_{i}=\operatorname{argmax}\left(\Omega_{i}\right)^{\alpha}\left(\Lambda_{i}\right)^{1-\alpha}, i=1,2
$$

whereas, in the case of profit sharing is

$$
\varpi_{i}, \lambda_{i}=\operatorname{argmax}\left(\Omega_{i}\right)^{\alpha}\left(\Lambda_{i}\right)^{1-\alpha}, i=1,2
$$

where the parameter $\alpha \in[0,1]$ captures the parties' relative bargaining strength. While in Sørensen (1992) the value of $\alpha$ differs across bargaining units in the industry, this 


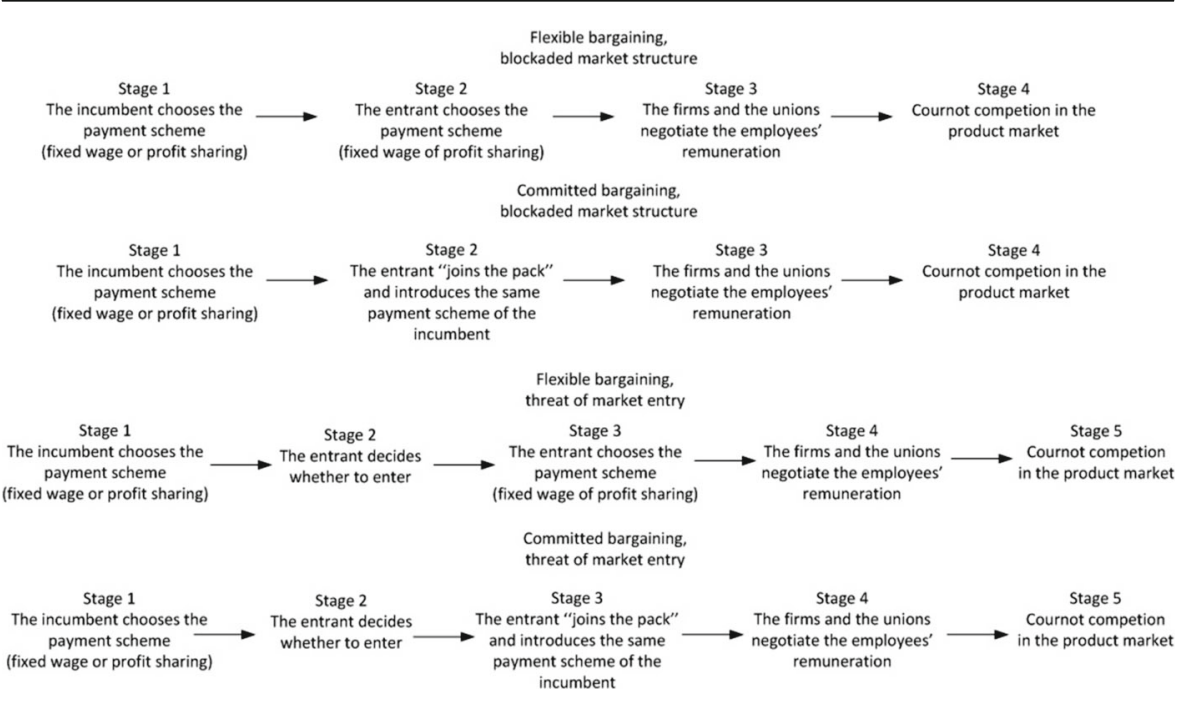

Fig. 2 Timing of the game

work assumes that the relative power is equal (see Bughin 1999; Buccella 2011).

In the same vein as Bughin (1999) and Buccella (2011), the paper selectively analyzes two alternative market structures and two modes of potential entry. Concerning the market structure, first is considered a given duopoly and second a monopoly facing a threat of entry. As regards the modes of entry, first the focus is on committed bargaining: the incumbent firm selects the payment scheme, and then the entrant "joins the pack" and introduces the predominant payment scheme as required by the industry practice. Second, the analysis concentrates on flexible bargaining, where the potential entrant can freely choose which payment scheme to introduce in the negotiations. $^{4}$

The game is solved in the backward fashion to derive sub-game perfect Nash equilibria. Depending on the market structure, the game is a four/five-stage game, and the sequence of moves is as follows. In the first stage, the incumbent firm chooses which payment scheme to introduce into negotiations, that is, either fixed wage $(\mathrm{FW})$ or profit-sharing (PS). In the case of duopoly, in the second stage the entrant, given the range of its possibility range, decides which payment scheme introduce. In the case of monopoly with threat of entry, in the second stage, the potential entrant, on the basis of its possibilities, decides whether to enter in the industry, whereas in the third stage it selects the payment scheme. The last two stages are common, independent of the market structures and order of moves in the first-stage(s) of the game. In the second-tolast stage, the unions and the firms bargain over the employees' remuneration. Finally, firms engage in Cournot competition, choosing profit-maximizing quantities and realizing output. Figure 2 exemplifies the timing of the game.

Making use of equations (1)-(7) and solving the bargaining problems in (8) and (9), direct (although tedious) calculations lead to the results in Table 1, which describes monopoly and duopoly outcomes. With regard to the duopoly market structure, each bargaining combination is inspected.

\footnotetext{
${ }^{4}$ Note that, in the case of flexible bargaining with homogeneous firms, the potential entrant choosing the same pay scheme as the incumbent does not characterizes a committed bargaining.
} 

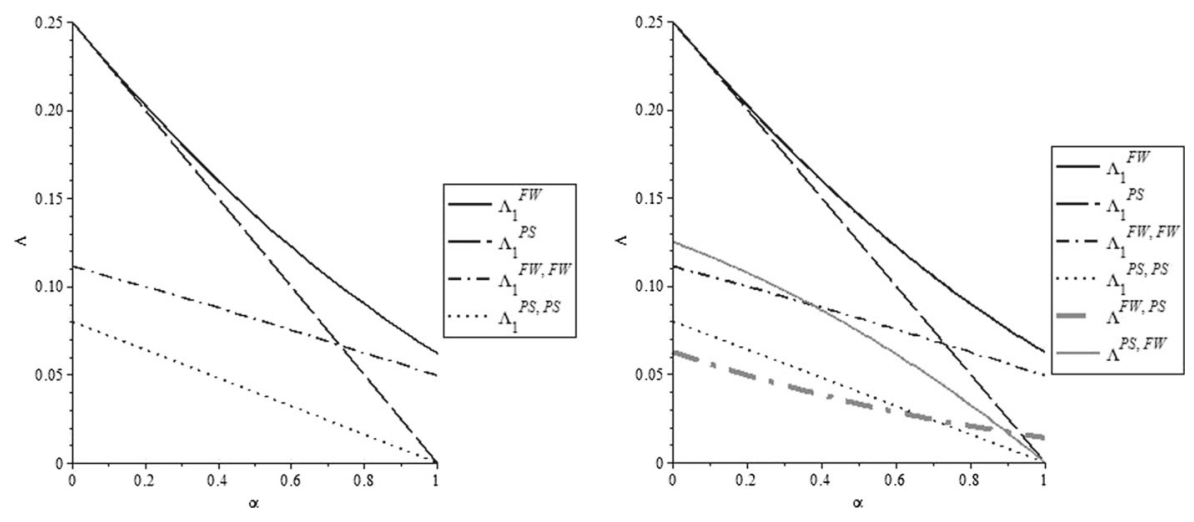

Fig. 3 Relevant owners income levels: "committed bargaining" (left box) and "flexible bargaining" (right box)

Findings in Table 1 equal those of Sørensen (1992), with $\beta=0$ in eq. (4) (where $\beta$ stands for an outside remuneration alternative for workers), and $a, b=1$ in eq. (6) (where $a, b$ are the demand parameters) of the above mentioned work. ${ }^{5}$ Figure 3 depicts the relevant owners income payoffs for the case of "committed bargaining" (left box), and "flexible bargaining" (right box).

At first, consider the situation of duopoly as the given market structure, i.e., the case of $E=0$. As to firms, net profits in the case where both selects the profit sharing scheme (the PS-PS case) are lower than when both selects the fixed wage scheme (the FW-FW case) whatever is the union bargaining strength. In formal terms, $\Lambda_{1}^{P S, P S}<\Lambda_{1}^{F W, F W}$, $\forall \alpha \in[0,1]$, where the first upper script denotes the firm's selected payment scheme, while the second indicates that of the rival firm. Hence, under committed bargaining, the incumbent chooses FW; the entrant is forced to "join the pack": the Nash equilibrium is the introduction of a FW scheme in the industry.

Under flexible bargaining, straightforward payoffs' comparison reveals that PS is the entrant's dominant strategy for $\alpha \in[0, .37)$; therefore, the incumbent chooses the remuneration scheme comparing $\Lambda_{1}^{P S, P S}$ and $\Lambda_{1}^{F W, P S}$. Since $\Lambda_{1}^{P S, P S}>\Lambda_{1}^{F W, P S}$ for $\alpha \in[0, .37)$, it follows that in this range of the unions' bargaining power the overall adoption in the industry of the PS scheme is the Nash equilibrium. For $\alpha \in(.37, .69]$, if the incumbent introduces $\mathrm{FW}$, the entrant selects $\mathrm{FW}$ as well, since $\Lambda_{2}^{F W, P S}>\Lambda_{2}^{P S, P S}$, while if the incumbent introduces PS, the entrant does the same because $\Lambda_{2}^{P S, P S}>\Lambda_{2}^{F W, P S}$. Hence, the incumbent chooses the pay scheme comparing $\Lambda_{1}^{P S, P S}$ and $\Lambda_{1}^{F W, F W}$. Given that for $\alpha \in(.37, .69] \Lambda_{1}^{F W, F W}>\Lambda_{1}^{P S, P S}$, in this range of the unions' relative strength, $\mathrm{FW}$ is the Nash equilibrium payment scheme. Finally, for $\alpha \in(.69,1]$, FW is the entrant's dominant strategy. Consequently, the incumbent chooses the pay scheme comparing $\Lambda_{1}^{P S, F W}$

\footnotetext{
${ }^{5}$ Note that the equilibrium base wage of the firms adopting PS in duopoly is negative. Nonetheless, to observe such wage contracts in practice is unrealistic. This result depends on the assumption of risk-neutral trade unions and the normalization to zero of the outside remuneration for workers. Sørensen (1992) and Göddeke (2010) point up that the PS bargaining units optimally agree on a base wage below the outside remuneration to expand employment (output) above the labor demand and maximize their joint utilities (i.e., the size of the "cake" to share). Therefore, the effect of introducing the PS scheme is that of accelerating product market competition, similar to the logic behind that of delegation games with non-unionized managers (e.g., Fershtman and Judd 1987).
} 


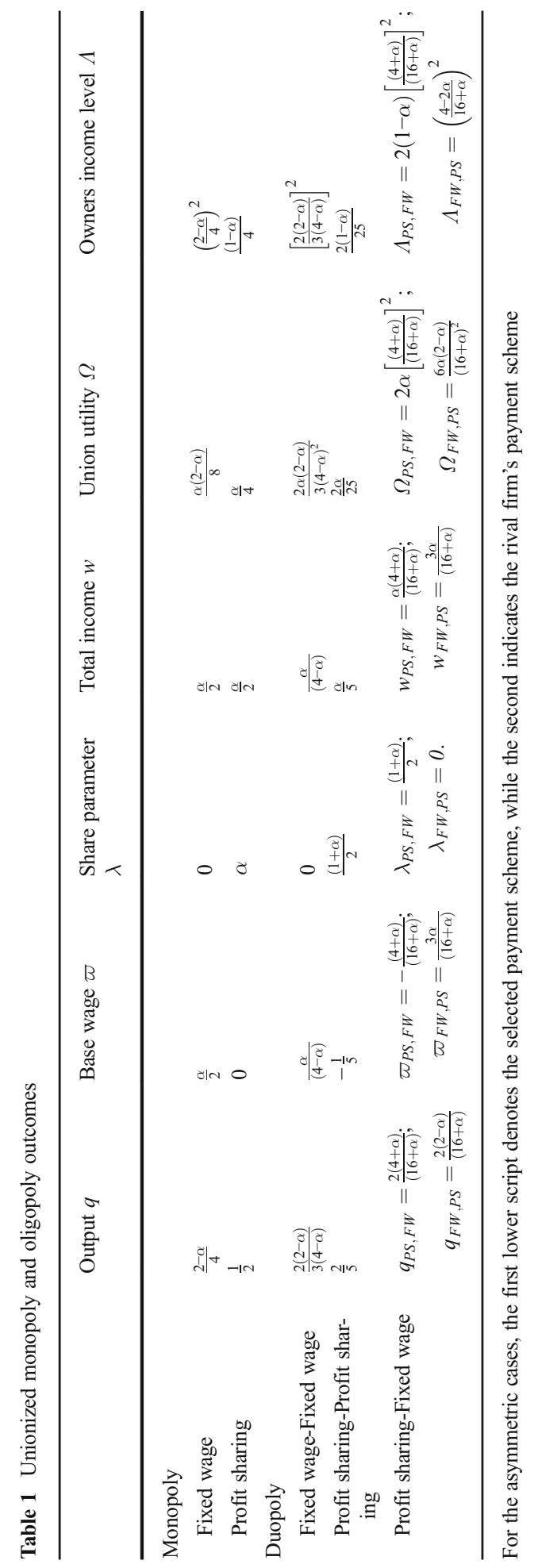


and $\Lambda_{1}^{F W, F W}$. For $\alpha \in(.69,1]$, it turns out that $\Lambda_{1}^{F W, F W}>\Lambda_{1}^{P S, F W}$ : hence, the overall introduction in the industry of the FW scheme is the Nash equilibrium.

On the other hand, it can easily be checked that the PS scheme is always the dominant strategy from the unions' point of view, both under committed and flexible bargaining. This result implies that, in the case of committed bargaining, the firms introduce the FW in a clear conflict of interests with their unions. However, in the case of flexible bargaining, for $\alpha \in[0,37)$, the firms can introduce the PS pay scheme without conflict of interests with unions. These findings can be summarized in the following proposition.

Proposition 1: In a unionized duopoly with a RTM framework, the introduction of the $F W$ pay scheme is the dominant strategy for firms under committed bargaining; this is in explicit conflict of interests with the unions since the PS is their dominant strategy. On the other hand, under flexible bargaining, if $\alpha \in[0, .37)$, the firms choose to introduce the PS pay scheme, and no conflict of interests with unions arises. However, for $\alpha \in[.37,1]$, the firms select the $F W$ pay scheme, again in conflict with unions' interests.

Sørensen (1992) explains the rationale for these results. If the unions have strong enough bargaining power, the firms always select the FW scheme. In fact, in the case of the PS payment scheme, the total utility of the bargaining unit, $\Lambda_{i}+\Omega_{i}$, does not depend on the relative strength of the parties: firm $i$ and union $i$ optimally agree on a base wage $\varpi_{i}$, independent of the bargaining power, to maximize the sum of their utilities. Then, the parties use the parameter $\lambda_{i}$, which depends on the relative negotiation strength, to share the total utility. However, the stronger the unions are, the smaller is the share of the total utility that goes to firms. As Sørensen (1992) underscores, in the limit case of unions having full bargaining power, the firms get a zero payoff under the PS scheme while, under the FW scheme, firms obtain a positive payoff. The reason resides in the fact that, in the bargaining process under a PS scheme, the unions control two independent instruments (the base wage and the profit sharing parameter) to attain the maximal possible values of their two goal variables (employment and income per worker), implying that the unions capture all the oligopoly rents. Per contra, in the case of bargaining under a FW scheme, the unions have one instrument but two goal variables. Therefore, there is a trade-off between income and employment levels and the unions choose a wage rate leading to positive profits to the firms.

Proposition 1 also states that, whatever is the entry mode in the industry, for a given bargaining framework (the RTM model), there are conditions such that the flexibility of choosing the payment scheme eliminates the conflict of interests among the bargaining parties. This result contrasts with the findings of Buccella (2011) where, for a given payment scheme (FW), the flexibility of choosing the scope among EB or RTM never eradicates the parties' conflict of interests as regards the bargaining agenda.

Consider now the case of threat of entry. Similar to the reasoning of Bughin (1999) and Buccella (2011), in the case of monopoly with threat of market entry under "committed bargaining", the incumbent $(M)$ can strategically select the payment scheme as an entry deterrence tool. Given the payoff structure in the "committed bargaining" game in Fig. 3, left box, a preliminary observation allows to simplify the subsequent analysis by focusing on a restricted range of the fixed costs size the entrant faces. 
Restriction $1 \Lambda_{1}^{F W, F W}>E>\Lambda_{1}^{P S, P S}$

The economic meaning of Restriction 1 is straight forward. In fact, if $\Lambda_{1}^{P S, P S}>E$, the level of the fixed costs is low enough that entry in the industry is always free. On the other hand, if $E>\Lambda_{1}^{F W, F W}$, the size of the fixed costs is prohibitively high for the potential competitor that market entry is always blockaded. Given Restriction 1, the following Lemma applies.

Lemma 1: The incumbent can strategically select the use of a pay scheme to deter entry if the following conditions apply:

$$
\text { a) } \left.\Lambda_{1, M}^{i}>E>\Lambda_{1}^{i, i} \quad i=F W, P S ; \quad b\right) \Lambda_{1, M}^{i}>\Lambda_{1}^{j, j} \quad i, j=F W, P S \text {. }
$$

Let us discuss conditions $(a)-(b)$ in Lemma 1. Condition $(a)$ simply states that, under committed bargaining, if the incumbent negotiates with the union a precise pay scheme, fixed costs higher than the gross duopoly profits with that pay scheme block the potential competitor because entry is no longer profitable. Condition $(b)$ specifies that the duopoly profits with the alternative pay scheme do not have to be larger than the monopoly profits of the selected pay scheme because, otherwise, the incumbent finds more profitable to choose the alternative pay scheme and accommodate entry. Application of Lemma 1 under Restriction 1 to firms' gross profits outcomes in Table 1 leads directly to the following proposition.

Proposition 2: If the union's relative bargaining power ranges in $\alpha \in[0,73)$, under "committed bargaining" the PS pay scheme can be used as a market entry deterrent in the unionized sector without generating a conflict of interests between the bargaining parties.

Proof: see the Appendix.

Proposition 2 asserts that, if the union facing the incumbent firm has a "not too high" bargaining power, the introduction of a PS payment scheme can be utilized as an effective instrument to deter potential entry in the industry. Moreover, if it is contemplated the possibility of a side-payment from the union to the incumbent firm, entry deterrence can be fully implemented. The union active in the incumbent firm also loses due to of market entry: in fact, the utility differential is $\Delta\left(\Omega_{1}\right)=\Omega_{1, M}^{P S}-\Omega_{1, D}^{F W} \geq 0, \forall \alpha \in[0,1]$, where the subscripts $M$ and $D$ stand for monopoly and duopoly, respectively. It can be shown that, at the value of $\alpha=.295$, before the threshold of $\alpha=.73$, the union utility differential compensates the maximum contraction of the profits of the incumbent $\left.\Delta\left(\Pi_{1}\right)\right|_{\alpha=1}=\Pi_{1, M}^{P S}-\Pi_{1, D}^{F W}=-4 / 81 .^{6}$

The analysis becomes more articulated when the monopoly with threat of market entry under "flexible bargaining" is considered. The strategic selection of the pay

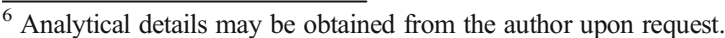


scheme strongly depends on the union's power and the size of the fixed costs. This complex interaction leads to a rich set of equilibrium summarized in the following proposition.

Proposition 3: The threat of market entry under "flexible bargaining" generates the subsequent equilibria:

1) if $\alpha \in[0, .37)$ :

- for $E \in\left[0, \Lambda_{1}^{P S, P S}\right]$, the equilibrium market structure is a duopoly with all firms adopting $P S$;

- for $E \in\left(\Lambda_{1}^{P S, P S}, \Lambda^{P S, F W}\right]$, the incumbent strategically selects $P S$ to deter entry, and monopoly is the market structure;

2) if $\alpha \in[.37, .73)$ :

- for $E \in\left[0, \Lambda^{F W, P S}\right]$, the equilibrium market structure is a duopoly with all firms adopting $F W$;

- for $E \in\left(\Lambda^{F W, P S}, \Lambda_{1}^{F W, F W}\right]$, the incumbent strategically selects PS to deter entry, and monopoly arises as the market structure;

3) if $\alpha \in[.73,1]$ :

- for $E \in\left[0, \Lambda_{1}^{F W, F W}\right]$, the equilibrium market structure is a duopoly in which both firms select the FW pay scheme in conflict with unions' interests.

Since PS is always the unions' most preferred remuneration scheme, as a result it can be broadly used as a market entry deterrent tool without generating a conflict of interests between the bargaining parties.

Proof: see the Appendix.

These novel results have noteworthy consequences in terms of insights for labor market regulations and antitrust and competition policies. Indeed, if the labor market institutions in a country do not consider that employment enters the bargaining protocol, the selection of the payment scheme, which is usually left to the parties' bargaining freedom, becomes a strategic deterrence tool that may create dominant positions in unionized industries. Nonetheless, a cautionary remark is here required. The findings of this work do not apply when the negotiation agenda includes employment, i.e., in the presence of the efficient bargaining institution. In fact, as well known, Anderson and Devereux (1989) have shown that in a unionized monopoly, under rather general assumptions, RTM and EB negotiations with profit sharing generate identical bargaining outcomes that also duplicate those of EB with fixed wages. As a consequence, the incumbent under EB obtains equal bargaining outcomes irrespective of the pay schemes and loses a tool to deter market entry.

\section{Conclusions}

This paper has built a simple, though enlightening, model to investigate which pay scheme arises in equilibrium in a unionized duopoly with potential market 
entry, and the potential role that pay schemes can have as entry deterrence mechanism. The work has considered a sequential move games where, in the first stage, the incumbent firm (the first-mover player) selects to negotiate either a fixed wage or a profit sharing system; then, the entrant (the second-mover player), decides whether to enter in the industry. In the second stage, the unions and the firms bargain over the employees' remuneration. In the last stage of the game, firms compete á la Cournot in the product market. The paper has analyzed both the duopoly and the monopoly with threat of entry market structures as well as committed and flexible bargaining.

The main points of the paper are as follows. The market structure, the entry mode and the parties' relative bargaining strength affects the equilibrium pay scheme in the industry. The incumbent's choice between fixed wage and profit sharing influences the market entry decision because of the impact on the potential rival's profitability. Unions always prefer the profit sharing scheme. In the case of flexible bargaining, the firms choose the profit sharing only if the unions' power is not large. On the other hand, in the case of committed bargaining, depending on the market structure, either the fixed wage or the profit sharing system may emerge in equilibrium.

Two novelties arise from these results. Firstly, for a given bargaining framework (the RTM), the flexibility of choosing the pay scheme creates, under certain conditions, a common interest as regards the agenda of the negotiations: unions and firms may agree about the introduction of the profit sharing scheme. This contrasts with earlier findings showing that, for a given pay scheme (the fixed wage), the flexibility of choosing the bargaining scope never eliminates the parties' conflict of interests concerning the agenda. Secondly, if the union facing the incumbent firm is not too strong, the bargaining parties can introduce profit sharing into the negotiations to deter potential entry in the industry. Therefore, the work has shown that the pay scheme can be used as a strategic entry deterrent instrument during the bargaining process, provided that employment does not enter the bargaining protocol.

The paper is built on a set of precise assumptions. To check the robustness of the results, a direct extension can be the introduction of different production technologies such as a convex cost function. Another suitable direction of analysis is to investigate whether the Bertrand competition mode with differentiated products may alter the equilibria of the game. Furthermore, the firms may introduce other performance related pay schemes such as piece-rate. Finally, the model has considered the case of perfect symmetry in unions' bargaining power and labor productivity. However, Mukherjee and Wang (2013) provide new appealing insights on the effects of different labor productivities among firms on market entry in a unionized oligopoly. These observations may stimulate further research.

Acknowledgments I am extremely grateful to Odd Rune Straume, Co-Editor of this Journal, and two anonymous referees for their extremely helpful comments and suggestions that have substantially enhanced the clarity and quality of the paper. All remaining errors are, of course, my sole responsibility. Usual disclaimer applies. 


\section{Appendix}

\section{Proof of Proposition 2}

For $\alpha \in[0, .73)$, the profits' payoff ranking for the incumbent firm is $\Lambda_{1, M}^{F W}>\Lambda_{1, M}^{P S}>\Lambda_{1}^{F W, F W}>\Lambda_{1}^{P S, P S}$ (see also Fig. 3). Thus, given Restriction 1, it is obtained that $\Lambda_{1, M}^{F W}>\Lambda_{1, M}^{P S}>\Lambda_{1}^{F W, F W}>E>\Lambda_{1}^{P S, P S}$ : only the PS scheme concurrently satisfies conditions $(a)-(b)$ in Lemma 1 . In fact, if the incumbent selects $\mathrm{FW}$, the level of the fixed costs is such that entry cannot be impeded. Therefore, the incumbent obtains $\Lambda_{1}^{F W, F W}$. However, if the incumbent commits to PS, the competitor cannot enter the market, and the incumbent achieves $\Lambda_{1, M}^{P S}>\Lambda_{1}^{F W, F W}$.

On the other hand, for $\alpha \in[.73,1]$, the profits' payoff ranking for the incumbent becomes $\Lambda_{1, M}^{F W}>\Lambda_{1, M}^{F W, F W}>\Lambda_{1, M}^{P S}>\Lambda_{1}^{P S, P S}$ : FW is the dominant strategy for the incumbent (irrespective of $E$ ) and PS cannot be strategically used to deter entry.

\section{Proof of Proposition 3}

For $\alpha \in[0,37)$, if the incumbent chooses PS and $E \leq \Lambda_{1}^{F W, P S}$, the analysis equals that of duopoly. However, if $E \in\left(\Lambda^{F W, P S}, \Lambda_{1}{ }^{P S, P S}\right)$ and the incumbent chooses PS, the competitor can enter only if it selects PS while, if the incumbent chooses FW, the entrant again selects PS because $\Lambda_{2}^{P S, F W}>\Lambda_{2}^{F W, F W}$. Hence, the incumbent chooses its remuneration scheme comparing $\Lambda_{1}^{P S, P S}$ and $\Lambda_{1}^{F W, P S}$. Since $\Lambda_{1}^{P S, P S}>\Lambda_{1}^{F W, P S}$ (see Fig. 3, right box), the overall adoption in the duopoly industry of the PS scheme is the Nash equilibrium. On the other hand, if fixed costs are such that $E \in\left(\Lambda^{P S, P S}, \Lambda_{1}{ }^{F W, F W}\right)$, entry does not take place when the incumbent selects PS; however the competitor can enter if the incumbent selects FW. In this case, the entrant chooses PS because $\Lambda_{2}^{P S, F W}>\Lambda_{2}^{F W, F W}$. Thus, the comparison between $\Lambda_{1, M}^{P S}$ and $\Lambda_{1}^{F W, P S}$ determines the incumbent choice of the remuneration scheme, and the incumbent selects PS because $\Lambda_{1, M}^{P S}>\Lambda_{1}^{F W, P S}$ : the equilibrium industry structure is a monopoly. If $E \in\left(\Lambda_{1}^{F W, F W}, \Lambda^{P S, F W}\right)$, again the entrant does not enter if the incumbent selects PS; however, when the incumbent selects FW, the competitor can enter only if it chooses PS. Thus, the incumbent's selection of the remuneration scheme occurs via the comparison of $\Lambda_{1, M}^{P S}$ and $\Lambda_{1}^{F W, P S}$. Since it is repeatedly that $\Lambda_{1, M}^{P S}>\Lambda_{1}^{F W, P S}$, the incumbent opts for PS and the industry remains a monopoly. Finally, if $E>\Lambda^{P S, F W}$, the incumbent obtains $\Lambda_{1, M}^{F W}$ and entry never occurs.

In the range $\alpha \in[.37, .69)$ (see also Fig. 3, right box), for $E \leq \Lambda^{F W, P S}$ the analysis mirrors that of duopoly, and for $E \in\left(\Lambda^{F W, P S}, \Lambda_{1}{ }^{P S, P S}\right)$ it equals the one carried out in the paragraph above. When the fixed costs are $E \in\left(\Lambda^{P S, P S}, \Lambda^{P S, F W}\right)$ entry does not occur if the incumbent selects PS; however, in the case the incumbent selects FW, the rival can enter the industry and selects FW because now, for $\alpha \in[.37, .69), \Lambda_{2}^{F W, F W}>\Lambda_{2}^{P S, F W}$. As a consequence, the incumbent chooses the remuneration scheme to negotiate comparing $\Lambda_{1, M}^{P S}$ and $\Lambda_{1}^{F W, F W}$, and given that $\Lambda_{1, M}^{P S}>\Lambda_{1}^{F W, F W}$ the incumbent selects PS: the industry remains a monopoly. If $E \in\left(\Lambda^{P S, F W}, \Lambda_{1}{ }^{F W, F W}\right)$ entry does not occur if the incumbent selects PS; however, in the case the incumbent selects FW, the rival can now enter the industry only if it selects FW. Therefore, the incumbent again selects the remuneration 
scheme to negotiate comparing $\Lambda_{1, M}^{P S}$ and $\Lambda_{1}^{F W, F W}$, and given that $\Lambda_{1, M}^{P S}>\Lambda_{1}^{F W, F W}$ the PS scheme is adopted: the industry remains a monopoly. If $E>\Lambda_{1}^{F W, F W}$, the incumbent gets $\Lambda_{1, M}^{F W}$ and entry never occurs.

In the range $\alpha \in[.69, .73)$, for $E \leq \Lambda_{1}^{F W, F W}$, entry is always profitable; thus, the analysis reflects that of duopoly. However, if $E \in\left(\Lambda_{1}^{P S, P S}, \Lambda^{F W, P S}\right)$ and the incumbent selects PS, the entrant can get market access only if it selects FW. On the other hand, if the incumbent chooses $\mathrm{FW}$, the rival selects $\mathrm{FW}$ because $\Lambda_{2}^{F W, F W}>\Lambda_{2}^{P S, F W}$. Accordingly, for $E \in\left(\Lambda_{1}^{P S, P S}, \Lambda^{F W, P S}\right)$, the incumbent decides the pay scheme to negotiate comparing $\Lambda_{1}^{P S, F W}$ and $\Lambda_{1}^{F W, F W}$. Given that $\Lambda_{1}^{F W, F W}>\Lambda_{1}^{P S, F W}$, the incumbent chooses FW. As a result, a duopoly characterized by FW arises in equilibrium. When the fixed costs are $E \in\left(\Lambda^{F W, P S}, \Lambda^{P S, F W}\right)$ and the incumbent selects PS, the entry does not occur; however, if the incumbent chooses FW, the entrant also selects FW because $\Lambda_{2}^{F W, F W}>\Lambda_{2}^{P S, F W}$. Hence, the incumbent's selection of the pay scheme occurs via comparison of $\Lambda_{1, M}^{P S}$ and $\Lambda_{1}^{F W, F W}$ : since $\Lambda_{1, M}^{P S}>\Lambda_{1}^{F W, F W}$ the incumbent chooses PS, entry is deterred and the equilibrium market structure is a monopoly. If $E \in\left(\Lambda^{P S, F W}, \Lambda_{1}^{F W, F W}\right]$, entry does not take place when the incumbent chooses PS while, when it selects FW, the entrant can enter only it selects FW. Again, the incumbent's remuneration choice is made comparing $\Lambda_{1, M}^{P S}$ and $\Lambda_{1}^{F W, F W}$, and given that $\Lambda_{1, M}^{P S}>\Lambda_{1}^{F W, F W}$, the incumbent chooses PS, there is no entry and the market structure in equilibrium is a monopoly. For $E>\Lambda_{1}^{F W, F W}$, the incumbent obtains $\Lambda_{1, M}^{F W}$ and entry does not take place whichever pay scheme it selects.

In the range $\alpha \in[.73,89)$, for $E \leq \Lambda_{1}^{P S, P S}$, entry is always profitable; thus, the analysis reflects that of duopoly. However, if $E \in\left(\Lambda_{1}^{P S, P S}, \Lambda^{F W, P S}\right]$ and the incumbent selects PS, the entrant can get market access only if it selects FW. On the other hand, if the incumbent chooses $\mathrm{FW}$, the rival selects $\mathrm{FW}$ because $\Lambda_{2}^{F W, F W}>\Lambda_{2}^{P S, F W}$. Therefore, for $E \in\left(\Lambda_{1}^{P S, P S}, \Lambda^{F W, P S}\right]$, the incumbent decides the pay scheme to negotiate comparing $\Lambda_{1}^{P S, F W}$ and $\Lambda_{1}^{F W, F W}$. Given that $\Lambda_{1}^{F W, F W}>\Lambda_{1}^{P S, F W}$, the incumbent chooses FW. As a result, a duopoly with all firms choosing $\mathrm{FW}$ as pay scheme arise in equilibrium. When the fixed costs are $E \in\left(\Lambda_{1}^{F W, P S}, \Lambda^{P S, F W}\right]$ and the incumbent selects PS, the entry does not occur; however, if the incumbent chooses FW, the entrant also selects FW because $\Lambda_{2}^{F W, F W}>\Lambda_{2}^{P S, F W}$. Hence, the incumbent's selection of the pay scheme occurs via comparison of $\Lambda_{1, M}^{P S}$ and $\Lambda_{1}^{F W, F W}$ : since $\Lambda_{1}^{F W, F W}>\Lambda_{1, M}^{P S}$ the incumbent chooses $\mathrm{FW}$ and accommodates entry. Therefore, the equilibrium market structure is a duopoly with all firms adopting FW. If $E \in\left(\Lambda^{P S, F W}, \Lambda_{1}^{F W, F W}\right]$, entry does not take place when the incumbent chooses PS while, when it selects FW, the entrant can enter only if it selects FW. Again, the incumbent's remuneration choice is made comparing $\Lambda_{1, M}^{P S}$ and $\Lambda_{1}^{F W, F W}$, and given that $\Lambda_{1}^{F W, F W}>\Lambda_{1, M}^{P S}$, the incumbent chooses $\mathrm{FW}$, entry is accommodated and the market structure in equilibrium is a duopoly. For $E>\Lambda_{1}^{F W, F W}$, entry does not take place whichever pay scheme the incumbent selects which gets $\Lambda_{1, M}^{F W}$.

Finally, in the range $\alpha \in[.89,1]$, as in the above paragraph, for $E \leq \Lambda_{1}^{P S, P S}$, the analysis replicates the results of duopoly. For $E \in\left(\Lambda_{1}^{P S, P S}, \Lambda^{F W, P S}\right]$ with the incumbent choosing the PS scheme, the competitor enters the market only if it selects FW. On the other hand, if the incumbent selects FW, the entrant can enter 1) selecting among the two pay schemes if $E \leq \Lambda^{P S, F W}$, and it chooses FW because $\Lambda_{2}^{F W, F W}>\Lambda_{2}^{P S, F W}$; and 2) only with FW if $E \in\left(\Lambda^{P S, F W}, \Lambda_{1}^{F W, F W}\right]$. Thus, the incumbent's choice in both cases is made comparing $\Lambda_{1}^{P S, F W}$ and $\Lambda_{1}^{F W, F W}$, and it selects FW because $\Lambda_{1}^{F W, F W}>\Lambda_{1}^{P S, F W}$ : the overall adoption in the duopoly industry of the fixed wage system is the Nash 
equilibrium. When the size of the fixed costs is $E>\Lambda^{F W, P S}$, if the incumbent opts for $\mathrm{PS}$, entry does not take place; however, if the incumbent chooses FW, for $E \in\left(\Lambda^{P S, F W}, \Lambda_{1}^{F W, F W}\right]$ the competitor enters only under $\mathrm{FW}$. Therefore, the incumbent compares $\Lambda_{1, M}^{P S}$ and $\Lambda_{1}^{F W, F W}$, and given that $\Lambda_{1}^{F W, F W}>\Lambda_{1, M}^{P S}$, it selects FW: entry s accommodated, and the equilibrium market structure is a duopoly with the overall adoption of the FW pay scheme. Finally, for $E>\Lambda_{1}^{F W, F W}$, the fixed costs are adequately high that entry never occurs, and the incumbent obtains $\Lambda_{1, M}^{F W}$.

Open Access This article is distributed under the terms of the Creative Commons Attribution 4.0 International License (http://creativecommons.org/licenses/by/4.0/), which permits unrestricted use, distribution, and reproduction in any medium, provided you give appropriate credit to the original author(s) and the source, provide a link to the Creative Commons license, and indicate if changes were made.

\section{References}

Anderson S, Devereux M (1989) Profit-sharing and optimal labour contracts. Can J Econ 22(2):425-433

Bain JS (1956) Barriers to new competition. Harvard University Press, Cambridge

Buccella D (2011) Corrigendum to "The strategic choice of union-oligopoly bargaining agenda" [Int. J. Ind. Organ. 17 (1999) 1029-1040]. Int J Industrial Org 29(6):690-693

Buccella D, Fanti L (2015) On the strategic choice of union-oligopoly bargaining agenda: further results. Econ Res Int 530890:1-7

Bughin J (1999) The strategic choice of union-oligopoly bargaining agenda. Int J Industrial Org 17(7):10291040

Chang C, Bjornstad DJ (1993) Profit, productivity, and profit-sharing. J Econ Finance 17(1):103-114

D'Art D, Turner T (2004) Profit sharing, firm performance and union influence in selected European countries. Personnel Rev 33(3):335-350

Dhillon A., Petrakis E. et al. (2001) Profit-sharing, Bertrand competition, and Monopoly Unions: a note. Warwick Economic Research Paper n. 612

Eurofound (2010) European company survey 2009: overview. Publications Office of the European Union, Luxembourg

Eurofound (2012) Fifth European working conditions survey: overview report. Publications Office of the European Union, Luxembourg

Fershtman C, Judd KL (1987) Equilibrium incentives in oligopoly. Am Econ Rev 77(5):927.940

Fung KC (1989) Profit-sharing and European unemployment. Europ Econ Rev 33(9):1787-1798

Gielen AC, Kerkhofs MJM, van Ours JC (2010) How performance related pay affects productivity and employment. J Population Econ 23:291-301

Göddeke A. K. (2010). Strategic profit sharing in a unionized oligopoly. Available at SSRN: http://ssrn.com/ abstract $=927365$.

Hoel M, Moene KO (1988) Profit sharing, unions and investments. Scandinavian J Econ 90(4):493-505

Jackman R (1988) Profit-sharing in a unionised economy with imperfect competition. Int J Industrial Org 6(1): 47-57

McDonald IM, Solow RM (1981) Wage bargaining and employment. Am Econ Rev 71(5):896-908

Mukherjee A, Wang LFS (2013) Labour union, entry and consumers welfare. Econ Lett 120(3):603-605

Nickell S, Andrews M (1983) Unions, real wages and employment in Britain 1951-79. Oxford Econ Papers 35:183-206

OECD (1995) Employment outlook 1995. OECD Publications, Paris

Pemberton J (1991) Profit sharing, unions and investment: an extension. Scandinavian J Econ 93(4):577-584

Petrakis E, Vlassis M (2000) Endogenous scope of bargaining in a union-oligopoly model: when will firms and unions bargain over employment? Labour Econ 7(3):261-281

Sørensen JR (1992) Profit-sharing in a unionized Cournot duopoly. J Econ 55(2):151-167

Vannini S, Bughin J (2000) To be (unionized) or not to be? A case for cost-raising strategies under Cournot oligopoly. Europ Econ Rev 44(9):1763-1781

Yang BZ (1995) Unionized oligopoly, labor-management cooperation, and international competitiveness. J Econ 62(1):33-53 